CUAD. CONTAB. / BOCOTÁ, COLOMBIA, 16 (42): 713-731 / SEPTIEMBRE-DICIEMBRE 2015 / 713

\title{
El papel de la auditoría forense en un caso de lavado de activos en Santiago de Cali*
}

doi:10.11144/Javeriana.cc16-42.pafc

\section{Jhonny Grajales-Quintero}

Contador público, Universidad del Valle. Profesor del Departamento de Contabilidad y Finanzas, Pontificia Universidad Javeriana, seccional Cali. Coordinador del grupo de investigación Pensamiento y Praxis.

Correo electrónico: yonnysgra@javerianacali.edu.co

\section{Karina del Carmen Hormechea-Jiménez}

Contadora pública, Universidad del Valle.

Correo electrónico: karina.hormechea@correounivalle. edu.co

\section{Brandon Andrés Trujillo-Guapacha}

Contador público, Universidad del Valle.

Correo electrónico: brandon.trujillo@correounivalle.edu.co

\footnotetext{
* Este trabajo de investigación es resultado del trabajo de grado para optar al título de contadores públicos en la Universidad del Valle, realizado por Brandon Andrés Trujillo-Guapacha y Karina Hormechea-Jiménez. El trabajo fue dirigido por el profesor Jhonny Grajales-Quintero.
} 
Resumen Este trabajo de investigación analiza, desde la perspectiva de la auditoría forense, un caso específico de lavado de activos en Santiago de Cali, Colombia. El objetivo del trabajo de investigación es examinar el procedimiento judicial y penal del caso de lavado de activos, teniendo en cuenta el papel cumplido por la auditoría forense en la búsqueda de fraude financiero. Esta investigación es un estudio de caso; se utilizó un método inductivo de investigación, lo cual permitió que se observaran las peculiaridades del caso objeto de estudio, al tiempo que hace posible la aplicación de los resultados obtenidos en otros casos de la misma índole.

Entre los principales resultados obtenidos, se encuentran los argumentos suficientes que se consideran evidencia o material probatorio para judicializar este caso de lavado de activos; además, se da a conocer cómo los procedimientos de auditoría forense fueron fundamentales para que las autoridades tomaran una decisión acerca del rumbo de los acusados y poder cerrar el caso. La investigación permite concluir que la auditoría forense jugó un papel relevante en la resolución del caso, ya que por medio de las herramientas que esta brinda se pudo esclarecer la realidad financiera que rodeaba a las personas implicadas en el delito.

Palabras clave Auditoría forense; investigación empírica; herramientas de auditoría forense; delitos económicos; lavado de activos; fraude; delitos financieros; procedimientos de auditoría; fraude financiero; incautación de dinero; procedimiento legal y normativo

\section{Código JEL M42}

\section{The Role of Forensic Auditing in an Asset Laundering Case in Santiago de Cali}

\footnotetext{
Abstract This research work analyzes, from a forensic audit perspective, a specific case of asset laundering in Santiago de Cali, Colombia. The purpose of this research work is to examine the judicial and criminal procedure of the asset laundering case taking into account the role pla-
}

yed by forensic auditing in the search of financial fraud. This research is a case study; we used an inductive research method. This made possible to observe the peculiarities of the case being studied while at the same time allowing the application of the results obtained in other cases of a similar nature. Among the main results obtained, we found a sufficient amount of arguments considered to be evidence or proving material to take to court this asset laundering case. Also, we show how the forensic audit processes were fundamental for authorities to take a decision regarding the destination of the defendants and be able to close the case. The research allowed us to conclude that forensic auditing played a relevant role in the resolution of the case since it was through the use of the tools forensic auditing brings that it became possible to shed light on the financial reality surrounding the people involved in the crime.

Keywords forensic auditing; empirical research; forensic audit tools; asset laundering; fraud; financial crimes; auditing procedures; financial fraud; money seizure; legal and regulatory proceeding

\section{Papel da auditoria forense em um caso de lavagem de ativos em Santiago de}

\section{Cali}

Resumo Este trabalho de pesquisa analisa, desde a perspectiva da auditoria forense, um caso específico de lavagem de ativos em Santiago de Cali, Colômbia. O objetivo do trabalho de pesquisa é examinar o procedimento judicial e penal do caso de lavagem de ativos, a levar em conta o papel cumprido pela auditoria forense na procura de fraude financeiro. Esta pesquisa é um estudo de caso; foi utilizado um método indutivo de pesquisa que permitiu observar as peculiaridades do caso objeto de estudo, ao tempo de tornar possível a aplicação dos resultados obtidos em outros casos da mesma índole. Como principais resultados obtidos aparecem os argumentos suficientes a considerar evidencia ou material provatório para julgar o caso como lavagem de ativos; além disso, é dado a conhecer como os procedimen- 
tos de auditoria forense foram fundamentais para que as autoridades tomassem decisão sobre o rumo dos acusados e conseguir fechar o caso. A pesquisa permite concluir que a auditoria forense teve papel relevante na resolução do caso, pois através das ferramentas que fornece foi possível esclarecer a realidade financeira em torno do pessoal envolvido no crime.

Palavras-chave Auditoria forense; pesquisa empírica; ferramentas de auditoria forense; crimes económicos; lavagem de ativos; fraude; crimes financeiros; procedimentos de auditoria; fraude financeira; confiscação de dinheiro; procedimento legal e normativo

\section{Introducción}

La auditoría es la técnica que permite verificar por medio de conocimientos contables que cada uno de los procesos de una empresa esté funcionando de forma adecuada. Ahora bien, la auditoría forense pretende recoger evidencia penal que permita tomar una decisión en firme sobre un determinado caso, comúnmente financiero.

Este trabajo de investigación tiene un enfoque empírico y pretende analizar, desde una perspectiva de la auditoría forense, un caso específico de lavado de activos, tomado directamente de la Fiscalía General de la Nación, cuyo proceso legal es llevado a cabo por el Juzgado Cuarto Penal del Circuito Especializado de la ciudad de Santiago de Cali. El objetivo de este trabajo de investigación es analizar todo el procedimiento judicial y penal del caso de lavado de activos, teniendo en cuenta la perspectiva de la auditoría forense y el papel cumplido en la búsqueda de fraude financiero. Esta investigación es un estudio de caso y utiliza un método inductivo, lo cual permite que se analicen las peculiaridades del caso objeto de estudio, se establece entonces una relación general que podría permitir la aplicación de los resultados obtenidos en otros casos de la misma índole.

La auditoría forense surge como herramienta para la atestación en los fraudes financieros, pues aporta los argumentos suficientes que se consideran evidencia para judicializar y dar por cerrado casos de este tipo. En otras palabras, se analiza todo el procedimiento judicial y penal del caso, teniendo en cuenta todos los aspectos de principio a fin, los cuales pueden llevar al origen del fraude, desde la perspectiva de la auditoría forense en la búsqueda de información contra el delito financiero.

Entre los principales resultados obtenidos, están la identificación de las pruebas suficientes que se consideran evidencia para judicializar este caso de lavado de activos; además, se da a conocer cómo los procedimientos de Auditoría fueron fundamentales para que las autoridades tomaran una decisión acerca del rumbo de los acusados y poder cerrar el caso. En cuanto a las conclusiones, esta investigación permitió identificar que la auditoría forense jugó un papel muy relevante en la resolución de este caso, ya que por medio de sus técnicas de investigación — como la vinculación de lo legal con los registros contables, los procedimientos analíticos a las pruebas recopiladas, el estudio de un caso específico para llegar a comprender su actividad en circunstancias importantes y una investigación descriptiva a partir de fuentes primarias y secundarias - se pudo esclarecer la realidad financiera que rodeaba a las personas implicadas en el delito. 


\section{6 / VOL. 16 / NO. 42 / SEPTIEMBRE-DICIEMBRE 2015}

Este artículo de investigación científica presenta los principales aspectos del trabajo de grado La auditoría forense en un caso específico de lavado de activos en la ciudad de Santiago de Cali. El documento presenta de manera detallada los resultados originales del trabajo de grado, un proyecto terminado de investigación, adaptado a los requerimientos de la revista Cuadernos de Contabilidad.

Además de esta introducción, este artículo se compone de tres capítulos, en el primer capítulo se detalla el procedimiento de la auditoría forense, un proceso que pretende utilizar los métodos utilizados en la auditoría de control interno y así recoger evidencia penal, que permita tomar una decisión en firme sobre un determinado caso, comúnmente financiero.

El segundo capítulo recopila los resultados de la investigación del caso de lavado de activos ocurrido en la ciudad de Santiago de Cali entre 2003 y 2010; detalla el análisis del caso real de delito financiero, cuyos cargos principales sobre los acusados fueron el de testaferrato y enriquecimiento ilícito y su proceso legal fue llevado a cabo por el Juzgado Cuarto Penal del Circuito Especializado de la misma ciudad.

Para finalizar, el tercer capítulo presenta el análisis del procedimiento de la auditoría forense en el caso de lavado de activos, teniendo en cuenta que la influencia de esta auditoría y sus procedimientos fueron fundamentales para permitir a las entidades legales tomar una decisión acertada acerca del rumbo de los acusados. Por tanto, es de gran importancia analizar y dar a conocer el papel que jugó la auditoría forense en la resolución de este caso, para poder brindar las pautas necesarias para reconocer y dar un fallo sobre un delito financiero.

\section{Metodología}

Esta investigación se basa en el estudio de casos, esto es, en "el estudio de la particularidad y de la complejidad de un caso singular, para llegar a comprender su actividad en circunstancias importantes" (Stake, 1999, p. 11). En otras palabras, un estudio de casos abarca la complejidad de un caso particular cuando se tiene un interés especial en él. Por lo tanto, el presente trabajo de investigación se aborda desde un estudio de caso, ya que el eje de indagación será un caso particular de lavado de activos, con el fin de comprender su actividad y su complejidad. Este abordaje desde un estudio de caso se fundamenta en que la investigación científica es una manera particular de observar la realidad; por esa razón, se complementa con el método inductivo de investigación.

El método inductivo es "un proceso en el que, a partir del estudio de casos particulares, se obtienen conclusiones o leyes universales que explican o relacionan los fenómenos estudiados" (Rodríguez-Moguel, 2005, p. 29), es decir, con este método se utiliza el razonamiento para obtener conclusiones que parten de hechos particulares, y se busca que la aplicación de estos resultados sea de carácter general, para así poder llegar a proponer leyes o principios universales. Ahora bien, hay dos tipos de inducción, la completa y la incompleta (Ruiz-Limón, 2006); la primera intenta conocer las características de todos los casos particulares para así afirmar con certeza una teoría que abarque todos los elementos estudiados, lo cual es casi imposible, ya que es muy difícil poder observar todos los objetos existentes; y la inducción incompleta, que es la más 
comúnmente realizada porque solo se pueden conocer las características de un cierto número de objetos, dejando espacio a investigaciones futuras que permitan la generalización. Para el estudio de la auditoría forense, se hace particularmente relevante la inducción incompleta porque permite que cada nuevo caso aumente las posibilidades heurísticas de investigación; así, los investigadores pueden apoyarse en las técnicas usadas previamente por otros investigadores. Pero esto solo es posible en la medida en que se publiquen los resultados de las investigaciones empíricas.

La presente investigación utilizó como fuente primaria los documentos que constituyeron el caso específico de lavado de activos en Santiago de Cali, obtenido directamente del Juzgado Cuarto Penal del Circuito Especializado de esta misma ciudad. También fueron fuentes primarias las personas que laboran en el Juzgado Cuarto Penal del Circuito.

A la información obtenida se le dio el siguiente tratamiento: se analizó la información contenida en las fichas de lectura, realizadas por cada texto leído que incluía datos relevantes para la investigación. También se estudió toda la documentación existente acerca del caso específico, para así identificar cuál sería la información pertinente para este trabajo. Además, se entrevistó a las personas que laboraban en el Juzgado, al momento de las visitas, como fuente de consulta para resolver cualquier inquietud sobre terminología, normatividad y procesos judiciales, entre otros aspectos.

El trabajo de investigación se realizó en las siguientes fases:

Fase I. Se describió el procedimiento de la auditoría forense, a partir de los planteamien- tos teóricos de diferentes autores especializados. Para ello, se usaron textos teóricos sobre el tema. Además, con base en las Normas de Auditoría Generalmente Aceptadas (NAGA), se estudió el procedimiento normativo de la auditoría y se contextualizaron la planeación, la ejecución y la conclusión, fases del procedimiento de auditoría.

Fase II. Se construye un marco conceptual sobre el crimen de lavado de activos a partir de fuentes académicas y un marco contextual, bajo las definiciones legales y normativas dadas en el Código Penal colombiano.

Fase III. Se procedió al análisis empírico de un caso de lavado de activos, que se identificó tras una cita con la jueza Flor Myriam Nieto, del Juzgado Cuarto Penal del Circuito Especializado. También se accedió al caso específico con la obligación de estudiarlo dentro de las instalaciones del Juzgado y respetar sus reglas, y con la sugerencia de omitir y cambiar los nombres de los verdaderos implicados para evitar problemas futuros y proteger su identidad. En esa medida, se realizaron visitas semanales al Juzgado Cuarto, y por medio de consultas a los funcionarios de esta entidad se pudieron resolver las preguntas e inquietudes que se presentaban al analizar cada folio del caso asignado. La descripción documental del caso se distribuía en tres cuadernos con información detallada desde la sospecha hacia el delincuente hasta el cumplimiento de su condena, el cuaderno uno constaba de 302 folios; el cuaderno dos, de 286; el tres tenía 52 y los anexos eran 138 folios, para un total de 778 folios útiles para estudiar el caso de lavado de activos.

Fase IV. En esta última fase, se identificó la relación existente entre el procedimiento de 
auditoría forense y el caso específico de lavado de activos. Utilizando la información recabada en las anteriores fases, se procedió a estudiar el papel de la auditoría forense en la investigación de este tipo de fraudes financieros. Para ello, el estudio del caso específico brindó las premisas necesarias para establecer la relación con las evidencias, las pruebas, el proceso contable y la doble contabilidad, entre otros aspectos reflejados en el caso que corresponden a un trabajo de auditoría.

Los procedimientos de auditoría a relacionar en este caso específico de lavado de activos, requieren los siguientes pasos: aspectos previos en los que se conocen el negocio, el sector económico y sus características; conocimiento de los registros contables utilizados; evaluación de posible ocurrencia de otros delitos dentro de él, por ejemplo, doble contabilidad; análisis de estados financieros; análisis de información y estudio de pruebas documentales. Se realizaron audiencias en las que diferentes testigos dieron declaraciones, pero no se agregaron. Aun así, estos procedimientos se reflejaron por medio de flujogramas y cuadros sinópticos para facilitar la comprensión del proceso de auditoría en este caso de lavado de activos (Cano, Lugo, Cano \& Cano, 2008).

\section{Aspectos conceptuales}

La auditoría es el proceso de verificación de la contabilidad en un determinado ente; por tanto, en este proceso de revisión, la auditoría forense busca recoger evidencias penales, por ejemplo del fraude financiero, es decir, eventos o actos intencionales por parte de uno o más individuos que implican el engaño para obtener una ventaja económica injusta o ilegal. A continuación, se describe cuál es el procedimiento de la auditoría forense.

\subsection{El procedimiento de auditoría forense}

La auditoría forense incide cuando se vincula lo legal con los registros contables, es más, este tipo de investigación requiere conocer también sobre aspectos operativos y administrativos, y solicitar apoyo de contadores experimentados con un alto grado de escepticismo. De una buena planeación, ejecución y conclusión del trabajo de auditoría, depende el éxito de la labor del auditor forense.

El procedimiento de la auditoría forense no representa gran diferencia con el procedimiento de la auditoría comúnmente utilizado. A continuación, se darán a conocer diferentes perspectivas de este procedimiento, según los planteamientos teóricos de diferentes autores especializados en el tema.

Para Donaliza Cano, Danilo Lugo, Miguel Cano y José Eriberto Cano (2008), el procedimiento de la auditoría forense debe propender por demostrar el origen de los recursos, con los cuales, en el caso de delito financiero, se generan diversas transacciones encaminadas a promover una actividad ilícita, ocultar la fuente del producto ilícito y evitar cualquier tipo de reportes u otros controles. Además, estos autores enfatizan que el procedimiento de auditoría forense se adapta a los requerimientos de cada caso; no obstante, la planeación, ejecución y conclusión del trabajo de auditoría, factores claves en este proceso, no varían. Así mismo, el auditor debe armonizar este proceso 
con la normatividad vigente (Cano, Lugo, Cano \& Cano, 2008). Con ello, el auditor forense debe conocer los aspectos que influyen en este procedimiento, desde el seguimiento de todas las pistas que llevan hacia los activos, pasivos, fuentes de fondos del sospechoso, ingresos excesivos injustificados y hasta registros ocultos fuera de la contabilidad, uso de diferentes terceros para desviar la información y registrarla en diferentes fechas y transacciones, maquillaje de estados financieros con datos falsos de su patrimonio real, uso del engaño que pone en duda su estado económico real, evasión de impuestos al no declarar su patrimonio y sus ingresos y falta grave al no estar constituido legalmente como empresa ni registrado como tal.

El procedimiento de auditoría llevado a cabo en determinado caso, tiende a caer en la dificultad de pretender fijar procedimientos sistemáticos. No obstante, la decisión de un juez o tribunal brinda la neutralidad y la certeza del desarrollo y la conclusión del proceso en un trabajo de auditoría. Con ello, la responsabilidad del auditor integral en este procedimiento solía ser bastante generalizada y, por tanto, uno de sus principales objetivos era el descubrimiento y la prevención de fraudes, según Rodrigo Estupiñán-Gaitán (2006); hoy en día, el auditor independiente procura reducir esta responsabilidad por medio de acuerdos con sus clientes, cartas de salvedad y observaciones, u otro tipo de declaraciones. La detección de fraudes es el principal objetivo de la auditoría forense, por ende, esta responsabilidad se extiende al auditor forense.

Además, "mediante el empleo cuidadoso y diligente de las normas y procedimientos de au- ditoría, un auditor puede llegar a la detección de muchas modalidades de fraudes o estafas, lo cual se refuerza si el auditor en su examen está atento a la posibilidad de que hayan ocurrido o se estén realizando actos ilegales que puedan tener efecto considerable sobre los estados financieros" (Estupiñán, 2006, p. 273). En otras palabras, el examen del auditor puede dar lugar a cualquier detección de fraudes, siempre y cuando su proceso sea el adecuado. Rodrigo Estupiñán-Gaitán infiere que antes de generar un proceso de auditoría similar al de la auditoría comúnmente utilizado, deben regir, en primer lugar, las normas y principios como garantes de un trabajo de calidad, así mismo el cumplimiento de estas en la ejecución del trabajo debe constituir el principal medio probatorio de la calidad y eficiencia de su función.

$$
\begin{aligned}
& \text { Las normas para la ejecución del trabajo } \\
& \text { proporcionan la metodología a seguir para } \\
& \text { cumplir el proceso de la auditoría, en con- } \\
& \text { cordancia con las pautas proporcionadas por } \\
& \text { las Normas Generales de Auditoría, es de } \\
& \text { anotar que las diferencias entre una audito- } \\
& \text { ría especial y una auditoría forense deberían } \\
& \text { ser mínimas en cuanto a los procedimien- } \\
& \text { tos establecidos (Estupiñán-Gaitán, 2006, } \\
& \text { p. 349). }
\end{aligned}
$$

Para finalizar, establecer un único procedimiento de auditoría forense implica identificar la existencia de varios planteamientos que buscan identificar el origen del fraude; anteriormente se realizó un resumen de los procedimientos aportado por Donaliza Cano, Danilo Lugo, Miguel Cano y José Eriberto Cano, y por 
Rodrigo Estupiñán-Gaitán. Aunque difieren en aspectos secundarios como la forma de denominar o agrupar cada aspecto del proceso, estos coinciden en lo importante: lograr el objetivo trazado desde la planeación, es decir, brindar un informe determinante respecto a la detección de fraude financiero.

Sin embargo, cada caso de fraude es único y requerirá procedimientos diseñados exclusivamente para cada investigación; puede haber casos similares, pero en general, no serán idénticos.

\section{Análisis de un caso de lavado de activos ocurrido en Santiago de Cali}

El caso corresponde al delito de lavado de activos, tomado de las instalaciones del Juzgado Cuarto Penal del Circuito Especializado, inició en 2003 y todo su proceso legal terminó en 2010.

La descripción documental del caso consta de tres (3) cuadernos:

Cuaderno 1: folio del 1 al 302; cuaderno 2: folio del 1 al 286 y cuaderno 3: folio del 1 al 52 y 138 folios de anexos. Total: 778 folios útiles ${ }^{1}$.

El jefe de grupo de homicidios de la Seccional de Investigación Criminal, Sijin, de la Dirección de Investigación Criminal de la Policía Nacional, Dijin, emitió la orden de iniciar una investigación a diferentes predios que venían presentando comportamientos sospechosos.

1 Salvedad: el presente caso es real. Por razones de seguridad, se han omitido los nombres del acusado, las personas implicadas, los denunciantes y sus direcciones, $u$ otros involucrados en este proceso. Los nombres y otros datos son ficticios.
El informe rendido por el jefe de la Sijin daba cuenta de movimientos no identificados y de la presencia de personas dedicadas a la realización de actividades delictivas; así la Fiscalía dispuso realizar un allanamiento a estos predios.

Entre los inmuebles allanados, la Fiscalía encontró la suma de \$33’687.000 pesos colombianos y US $\$ 81.993^{2}$ dólares estadounidenses, joyas avaluadas en unos $\$ 50$ '000.000 3 y recibos de pago de divisas a nombre de varias personas en casas de cambio de la ciudad, elementos que se consideraron suficientes para capturar a $\mathrm{Pa}$ blo Pérez y Juana Sánchez por los presuntos delitos de enriquecimiento ilícito y testaferrato.

Según el artículo 323 del Código Penal se incurre en el delito de lavado de activos,

Toda persona que adquiera, resguarde, invierta, transporte, transforme, custodie, o administre bienes que tengan su origen mediato o inmediato en diferentes actividades ilícitas o les dé a los bienes provenientes de dichas actividades apariencia de legalidad o los legalicen, oculten o encubran la verdadera naturaleza, origen, ubicación, destino, momento o derechos sobre tales bienes o realice cualquier otro acto, para ocultar o encubrir su origen ilícito.

Apoyada en este artículo, la Sijin decidió realizar el debido seguimiento, luego del cual se privó de la libertad a la pareja de esposos sospechosos de este crimen y se les dio una con-

\footnotetext{
2 Para este caso, la tasa representativa del mercado, TRM, utilizada es la del 5 de junio de 2003, fecha en la que la Sijin rindió informe. TRM $=\$ 2.849,71$.

3 Las cifras monetarias se trabajarán en la moneda en que se registraron en los cuadernos que conforman el caso.
} 
dena de 78 meses de prisión, una multa de 542 salarios mínimos mensuales legales vigentes, SMMLV (en ese entonces era \$332.000), equivalente a $\$ 179$ '944.000. Además, no se concedieron la suspensión condicional de la ejecución de la pena ni la prisión domiciliaria. Posteriormente, se realizó una investigación específica para esclarecer los hechos y la verdadera inocencia o culpabilidad de los procesados.

Antecedentes. El acusado Pablo Pérez se definía como comerciante, y su actividad comercial era la de préstamo de dinero, pero al realizar la debida investigación, se encontró que las afirmaciones hechas por las personas que lo rodeaban en su supuesta actividad económica no eran concordantes; por el contrario, no corresponden a ninguna secuencia lógica. Además, una de las mayores razones que implican al señor Pablo es que él no llevaba el registro contable de sus transacciones ni siquiera una lista de sus clientes; por tanto, no se podía establecer si el procesado ejercía una actividad de manera legal, puesto que incluso tratándose de un "negocio doméstico", como lo catalogó el defensor, ni siquiera se llevaron al proceso los libros de anotaciones donde aparecen esos registros, estando en plena posibilidad de hacerlo.

Se encontraron en poder del acusado recibos de giros provenientes de las casas de cambio, prueba que para el juez fue contundente y concluyó que se trataba de un caso de lavado de activos; no obstante, en su defensa, el señor Pablo explicó que estos recibos sirvieron para verificar el valor del dólar para la fecha de la transacción y mantener un "registro contable" de las deudas, versión que para el juez fue inaceptable cuando se relacionó que el proce- sado cobraba un interés por el préstamo, pues era claro que el valor del dólar podía fluctuar, lo que implicaba la posibilidad de que el acreedor perdiera, riesgo inaceptable para una persona que dice obtener su ingreso de la renta de capital y el cambio de divisas.

\section{Defensa del acusado. La defensa argu-} mentó que no se podía estar ante un delito de lavado de activos, dadas las pequeñas cantidades de dinero que ingresaban por este mecanismo, operación que vinculaba a un pequeño número de personas. El juez tampoco admitió este argumento como aceptable, ya que precisamente una de las modalidades más recurridas del lavado de activos es la conocida como "pitufeo" que opera mediante el envío de pequeñas sumas de dinero provenientes del exterior, por medio de casas de cambio, que son reclamadas en el país por personas que prestan su nombre como beneficiarios, con lo cual se encubre el origen ilícito de los bienes. Este mecanismo ha tomado auge en los últimos años, pues los sujetos vinculados al negocio ilícito se valen de diferentes personas que cobran los giros en cantidades reducidas y con ello evaden el control de las autoridades.

Transcurso de la investigación. Al ser reconocido el negocio, su actividad económica, la dirección, el nombre de Pablo Pérez como representante legal y otros datos de relevancia, se procedió a indagar al nombrado, debido a movimientos sospechosos aun no identificados.

Por tanto, el acusado se defendió con documentos soporte que supuestamente apoyaban la idea de que él es un verdadero comerciante, con registro de cámara de comercio; documento expedido por la red de cámaras de comercio 
Confecámaras con información financiera (aún no comprobada); y el documento "Inventario o detalle de los bienes o activos que posee y las deudas con corte".

Entre otros, la defensa entregó documentos que soportaban los cambios y giros en diferentes casas de cambio e intermediarias del mercado cambiario a nombre de diferentes personas y con diferentes montos. Estos documentos tenían su respectiva fecha y concordaban en el mismo mes, en un aparente proceso de legalidad en los cambios de divisas, y tenían sus debidas firmas con cédulas de ciudadanía; en cada uno de estos comprobantes del cambio de divisas constaba que estos ingresos son considerados no constitutivos de renta ni ganancia ocasional.

Por otra parte, el juzgado resolvió tomar las siguientes medidas para llevar este caso:

1. Escuchar de manera inmediata a los acusados

2. Remitir bajo custodia las joyas encontradas

3. Consignar los dólares al banco del país y dinero efectivo al banco ABC

4. Después de este procedimiento, se evaluará la libertad de los indagados

El señor Pérez se declaró inocente pues, según él, "nunca he tenido vínculos con narcotráfico, ni lavado de activos" y solicitó su libertad en compañía de su esposa, teniendo en cuenta que tienen dos hijos que quedaron solos en la casa.

Ahora, se remitieron bajo custodia las joyas encontradas, se envió un documento a la unidad de la fiscalía delegada ante los jueces especializados de Cali: Referencia, Custodia dólares, joyas y efectivo. Se remitió una caja sellada que contenía joyas para su custodia; igualmente, se entregaron \$33’687.000 pesos colombianos y US\$81.993 dólares estadounidenses.

La Unidad de la Fiscalía, ante los Jueces Especializados, tomó posesión del caso, con la relación del proceso, la declaración de los implicados que quedaron pendientes de resolver su situación jurídica y la remisión de bienes incautados, en un documento que consta de dos (2) cuadernos con 41 folios.

Sobre las grandes sumas de dinero encontradas físicamente en su lugar de domicilio, Pablo Pérez se justificó diciendo que prefiere guardarlas en su hogar en una caja de seguridad bajo llave, que guardarlas en un banco con el cobro del gravamen del tres por mil ( $3 \times 1.000)$, vigente entre los años 2000 y 2003, período en que transcurre esta investigación.

Ahora, frente a la gran inquietud que genera haber encontrado una serie de recibos de divisas transadas en casas de cambio, la respuesta de Pablo Pérez es que como él opera como prestamista, sus clientes, todos colombianos y residentes en este país, soportan su pago con dinero que les envían sus familiares desde el extranjero. Esta actividad es aparentemente legal. Pablo Pérez asegura este préstamo haciendo firmar a su cliente una letra o pagaré, documentos que tampoco tiene físicamente y que no puede presentar en el juzgado.

Otro aspecto que llama la atención de la Fiscalía es la fecha de registro ante la Cámara de Comercio, debido a que hacía apenas dos meses estaba registrado y, según su declaración, Pablo Pérez llevaba 12 años de arduo trabajo, pero, en lo que a registro se refiere, antes de eso no existía para el Comercio en Cali. La respues- 
ta a esta observación es que la pareja de esposos tan solo ahora es independiente.

El caso de Juana Sánchez, la esposa del señor en mención, se concluyó rápidamente y no se profirió medida de aseguramiento contra ella, ya que pruebas suficientes y los testimonios de proveedores dueños de establecimientos reconocidos en la ciudad - que en diferentes declaraciones aseguraron conocer a la señora Sánchez y presentaron documentos como facturas, remisiones y registros contables- permitieron demostrar la legalidad de su actividad económica y el origen lícito de sus bienes.

Pero la situación no es la misma con Pablo Pérez, pues sus argumentos no tenían base; además, no es creíble la explicación de los recibos procedentes del extranjero por préstamos hechos. "Nos encontramos ante una típica operación de lavado de dinero procedente de actividades ilícitas por desenmarañar", explicó Jairo Trujillo, investigador encargado del caso.

El investigador añade: "el hallazgo de $\$ 300.000 .000$ no puede adjudicarse al trabajo tesonero de 12 años, como si no hubiera una vida qué vivir, y sobre todo con los gastos del día a día", "la peregrina tesis de ser el resultado del esfuerzo con el sudor de la frente, como si la meta del hombre fuera solo atesorar, no se acepta por ahora".

Ahora bien, la Procuraduría General de la Nación y la Fiscalía General de la Nación procedieron a planear cómo se abordará la situación jurídica de Pérez y pidieron:

- Averiguar toda la procedencia de los documentos allanados en la casa de cambio Country, origen, valores, etc.
- Buscar también todo lo concerniente a Comercializadora de Joyas Don Pérez como cuentas corrientes y de ahorros, CDT, declaraciones de renta, estudio contable y financiero que permita descubrir si hay o no un incremento patrimonial injustificado.

- Recopilar declaraciones de los proveedores de Pablo Pérez.

- Permitir que el acusado muestre sus pruebas.

- Oficiar con destino a la Seccional de Investigación Criminal, Sijin; la Dirección de Investigación Criminal de la Policía Nacional, Dijin; el Departamento Administrativo de Seguridad, DAS; el Centro de Información sobre Actividades Delictivas, CISAD; y la International Criminal Police Organization, Interpol.

- Buscar la real identificación de Pablo Pérez en la Registraduría Nacional del Estado Civil.

Transcurrió un mes sin novedad en el caso y se enfrentó la decisión de cerrar la investigación en contra del señor Pablo y la señora Juana por falta de pruebas. Inés Román, procuradora judicial 69, envió una carta al Fiscal Sexto Especializado, en la que retomó resultados de la investigación por parte del detective Jairo Trujillo, además de toda la información recolectada hasta el momento, con el fin de oponerse a la decisión de cerrar la investigación sobre los procesados.

Gustavo Farfán, fiscal sexto, decidió no reponer para revocar la resolución mediante la cual se dispuso el cierre de la investigación, es decir, los presuntos delincuentes - Pablo y Juana-podían ser declarados inocentes. 
La procuradora Inés Román volvió a enviar carta al fiscal sexto especializado, en respuesta a la decisión que había tomado. En esta carta, la señora Inés retomó información brindada anteriormente y resaltó algunos aspectos sospechosos, como el hecho de que los clientes del señor Pablo pertenecieran a un mismo círculo familiar o de amigos cercanos; también alegó que no habían sido utilizados todos los mecanismos para obtener evidencia, como el uso de un perito contable, para comprobar que todos los movimientos financieros de los negocios de los acusados se encontraran en perfecto orden y acordes a la ley.

Luego, la Fiscalía Sexta retomó toda la información probatoria del caso, además de tener en cuenta las investigaciones del Ministerio Público y al final, resolvió varios puntos: profirió resolución de acusación en contra del señor Pablo por el presunto delito de lavado de activos y además, retiró los cargos sobre la señora Juana por el mismo presunto delito.

Entre las conclusiones que la Fiscalía obtuvo sobre el caso del señor Pablo estaban:

- El señor Pablo, en su investigación, no logró dar una explicación coherente sobre si el dinero que recibía era producto de actividades lícitas, por lo cual se presumió que este recurría al sistema "carrusel, pitufeo", por medio de ciertas personas para ingresar activos provenientes del narcotráfico del exterior y de Colombia.

- No había pagarés ni cartas de crédito ni letras que sustentaran los supuestos "créditos" del señor Pablo a unos "prestatarios", pues no tenía contabilidad.
- En el momento oportuno, no se recabó el material probatorio necesario para determinar que el acusado hubiese sido partícipe del cargo que se le imputaba.

- Aun así, se encontró culpable y después del estudio se le impuso una condena de 78 meses y una multa de 542 SMMLV.

Estas conclusiones fueron obtenidas por la Fiscalía, al analizar ciertas situaciones, como la inexistencia de testigos y audiencias, el hecho de no encontrar lícito el origen de algunos recibos de cambio y, además, el hecho de que por medio de investigaciones del CTI se descubrió que la señora Janeth Carrera, amante del señor Pablo, se alió junto con el acusado, al señor Camilo Gómez para recoger y reclamar el dinero en pequeñas cantidades, pagándoles a diferentes personas y familiares para que lo recogieran, haciéndose pasar por deudores del señor Pablo. Por estas razones, los dineros incautados en el allanamiento fueron dirigidos a formar parte del Fondo para la Rehabilitación, Inversión Social y Lucha contra el Crimen Organizado, FRISCO.

El 30 de agosto de 2010, el abogado José Arnulfo Piñeres envió carta a la Juez Cuarta Penal del Circuito Especializado, con el fin de sustentar el recurso de apelación, interpuesto contra la sentencia ordinaria del 30 de julio de 2010, por medio de la cual se resolvió condenar al señor Pablo como autor del delito de lavado de activos, a la pena de 78 meses de prisión y multa de 542 salarios mínimos legales mensuales vigentes, así como a la pena accesoria de inhabilidad para el ejercicio de derechos y funciones políticas por un lapso igual a la pena 
privativa de la libertad. Entre los motivos que fundamentan la apelación, se tiene que el acervo probatorio se reduce a un núcleo reducido de personas que acudieron donde el señor $\mathrm{Pa}$ blo, para negociar con él unos giros que provenían del exterior; estas personas dieron sus declaraciones explicando sus negocios con el acusado. Además, retomó el hecho de que los dineros incautados en el allanamiento fueron sustentados y su origen demostrado por la señora Juana.

Para finalizar, el 17 de mayo de 2011, la Sala del Juzgado concluyó que el delito resulta evidente, cuando sencillamente se acreditó que Pablo Pérez se valía de su amigo Camilo Gómez y las personas más cercanas a este, como su hermana Hilda Gómez, su esposa Luisa Bolaños, su sobrina Ana Gil y una vecina de nombre María Franco. Estas personas afirmaron en su declaración que el acusado les prestaba dinero en efectivo, con la excusa de que ellos pagaban esa deuda por medio de consignaciones emitidas por familiares desde el exterior, para ingresar el dinero que finalmente llegaba a manos del procesado.

Siendo ello así, para la Sala del Juzgado no hubo duda de que logró demostrarse que el señor Pablo recibió capitales de diferentes países. Y, aunque no logró detectarse, con certeza, la verdadera naturaleza del dinero, como lo ha establecido la jurisprudencia, ello no es argumento para descartar la existencia del delito de lavado de activos, puesto que el comportamiento consistió en aparentar legalidad, ocultando el origen del dinero utilizando a personas cercanas para recibir dineros del extranjero, siendo inequívoco pretender que, al desconocer la actividad ilegal de la que proviene el dinero, deba presumirse su legalidad.

Del análisis de las pruebas recaudadas en el proceso se concluyó que la conducta del señor Pérez giraba en torno a ocultar las divisas enviadas, al introducirlas al territorio nacional, evadiendo los controles; se corroboró entonces su responsabilidad en el punible de lavado de activos, por cuanto no se logró justificar de manera contundente el origen legal de las mismas y por el contrario, el juzgado consideró que el capital era proveniente de actividades ilegales, en las que el procesado actuaba como intermediario, cuando además — teniendo la oportunidad procesal para ejercer su derecho de defensa y demostrar lo contrariono logró demostrar en forma clara y coherente el origen de su ingreso.

Por lo tanto, se confirmó la sentencia 025 del 30 de julio de 2010, emanada por el Juzgado Cuarto Penal del Circuito Especializado de Cali, que condenó a Pablo Pérez por el delito de lavado de activos.

\section{Relación entre el procedimiento de auditoría forense y el caso de lavado de activos}

El procedimiento de la auditoría forense está relacionado en cada caso de delito financiero. Aunque su definición no sea reconocida ni se convierta en el eje al momento de realizar una investigación forense, el caso de lavado de activos escogido en este trabajo cuenta con cada uno de los pasos en el proceso de auditoría. 


\section{6 / VOL. 16/ NO. 42 / SEPTIEMBRE-DICIEMBRE 2015}

\subsection{Aspectos previos del negocio}

La Comercializadora de Joyas Don Pérez, según el acta de registro de la Cámara de Comercio de Cali, estaba registrada como un negocio que se dedicaba a la compra y venta de joyas en la ciudad; además de eso, Pablo Pérez, su representante legal, realizaba otra actividad económica: prestaba dinero a personas conocidas del sector y al momento de cancelar la deuda, el deudor pagaba en dólares, acto que para Pérez, constituía rentabilidad debido a que el valor del dólar fluctúa al cambiarlo en pesos. Así mismo, su esposa Juana Sánchez se dedicaba a la comercialización de artículos para dama, como joyas; cada proveedor le otorgaba crédito, para que ella de manera independiente realizara su propio negocio.

No obstante, esta actividad económica se convirtió en sospechosa cuando el Grupo de Homicidios de la SIJIN allanó el domicilio de esta pareja de esposos y encontró una cantidad de dinero que no concuerda con una actividad económica honorable, como lo explicó cada uno en su juicio. Esta cantidad de dinero equivale a $\$ 33.687 .000$ pesos colombianos, US\$81.993 dólares y joyas avaluadas en $\$ 50.000 .000$.

\subsection{Conocimiento de los registros contables}

Todas las empresas están en la obligación de llevar unos registros contables, los cuales permiten identificar la situación económica de la empresa. Aunque no todas las organizaciones llevan el mismo tipo de contabilidad, sí es necesario llevar al menos algún tipo de registro or- ganizado, que permita identificar la cantidad y el valor de las transacciones realizadas.

También es necesario que haya documentos que justifiquen y sustenten cada uno de los movimientos financieros que se realicen, ya que estos se convierten en prueba documental de cada uno de los registros contables realizados; además, brindan seguridad ya que sirven como respaldo al momento de presentarse cualquier tipo de inconveniente.

Según las declaraciones brindadas por los funcionarios de la Sijin, en el allanamiento del domicilio de los acusados no se encontraron pruebas documentales ni contables que sustentaran el correcto transcurso de las actividades económicas a las que supuestamente estos se dedicaban; tampoco había mínimos registros de las transacciones que, según los acusados, realizaban casi a diario y de las cuales vivían. Solo se encontraron unos cuantos apuntes que el señor Pérez tenía en un cuaderno, que incluían algunas de las cantidades de dinero que prestaba y a quién se las prestaba, pero sin ningún tipo de orden que permitiera a cualquier persona comprenderlos.

En cuanto a los documentos que respaldan las transacciones realizadas por los acusados, solo se encontraron recibos de giros provenientes de las casas de cambio, los cuales, según el señor Pérez, eran utilizados por él para verificar el valor del dólar al momento de realizar los intercambios con cada uno de sus supuestos clientes y así mismo poder asentarlos en sus "registros contables". Estas declaraciones no coincidían con los verdaderos hechos, ya que, según los acusados, el señor Pérez cobraba intereses sobre cada uno de los préstamos que ha- 
cía y esto, en una actividad económica real, no es rentable, ya que el prestamista corre un alto riesgo teniendo en cuenta que las divisas son muy fluctuantes y por lo tanto, podría perder algunas veces y otras ganar, hechos que no deben ocurrir en el transcurso normal de la actividad económica de este tipo de empresas.

Además, el procedimiento regular es simplemente tener una letra de cambio o pagaré firmado por la persona a la que se le prestó el dinero, documento suficiente para validar esa transacción, ya que en el caso en que se presentara cualquier inconveniente entre las partes, este serviría como prueba irrefutable en un juzgado, si se llegara a esa situación. En lugar de eso, el señor Pérez afirmaba que sus clientes luego de recibir sus giros enviados por sus familiares desde el exterior, le entregaban el documento, que se supone ellos deben conservar $y$, a cambio, él les regresaba la letra de cambio firmada por los clientes; estos actos son sospechosos ya que en este tipo de actividades no es relevante para el prestamista el comprobante del giro, ya que es un hecho independiente a la transacción del préstamo del dinero.

Ahora, en cuanto a la actividad principal a la que se dedicaba la esposa del acusado, la señora Sánchez, la de compra y venta de joyas, se encontró que la acusada no tenía registros contables sobre cada una de las transacciones que sostenía con las joyerías que le proveían su mercancía a crédito o en consignación; tampoco se encontraron asentadas estas transacciones en sus debidos registros, por parte de estas joyerías, hecho inusual, ya que - al ser empresas más grandes y más reconocidas- están obligadas a llevar una contabilidad ordenada que represente todos los intercambios de dinero y mercancía con cada uno de sus clientes y proveedores, sin importar la cuantía.

Sin embargo, sí había documentos que soportaban las transacciones sostenidas por la acusada y cada uno de sus proveedores, como facturas de compra y venta, cotizaciones y otros tipos de documentos informales realizados a mano que informaban acerca de la cantidad de dinero y mercancía adeudada; estos hechos demostraban, de alguna manera, que la señora Sánchez ciertamente se dedicaba a la compra y venta de joyas, como afirmó en sus declaraciones.

\subsection{Estudio de pruebas documentales}

La evidencia es parte fundamental de la auditoría forense, ya que esta es su fin, dado que su objetivo primordial es obtener pruebas que sirvan de base para poder emitir un fallo en un tribunal, acerca de un delito, que comúnmente es financiero. Por tal motivo, la evidencia que se obtenga debe ser tan suficiente y oportuna como sea posible, ya que va a permitir poder tomar una decisión importante sobre el curso de un caso.

\section{Búsqueda de pruebas documentales. La} Procuraduría y la Fiscalía General de la Nación decidieron que se investigaran todos los documentos encontrados en el domicilio de los acusados en el momento del allanamiento, como los comprobantes de las casas de cambio.

También planearon averiguar toda la información posible sobre Comercializadora de Joyas Don Pérez, la empresa de la que el señor Pérez es propietario, en especial en el ámbito financiero y contable, como cuentas bancarias 
y estados financieros que permitan identificar la situación real de la empresa. De igual forma, decidieron recopilar declaraciones provenientes de los proveedores del acusado y su esposa.

Estas entidades pidieron al Juzgado que tuviera en cuenta otros aspectos que pueden brindar evidencia suficiente para dar un veredicto; pruebas, como bienes muebles e inmuebles que están a nombre de los acusados; movimientos contables de la empresa del señor Pérez; certificados de existencia de representación legal de las casas de cambio relacionadas con el acusado, por parte de la Cámara de Comercio, además de otras formas que permitieran establecer la legalidad mercantil de estas compañías y el giro ordinario de sus negocios; también solicitaron realizar un estudio que implique experiencia y conocimiento para obtener un resultado significativo sobre los asientos contables de las joyerías Jeremías y Shaday, con el fin de aclarar el monto y la existencia de pasivos con la primera de estas, y con qué elementos se pretendía cancelar esas deudas, como también si había joyas en consignación y en tal caso, determinar cuáles serían; de igual manera, se pidió que un perito contable del CTI certificara bajo juramento, si - analizado lo anterior- hay un ingreso de dinero no reportado y no justificado a su patrimonio económico privado.

\subsection{El procedimiento de auditoría forense en el caso de lavado de activos ocurrido en la ciudad de Santiago de Cali}

En el caso de lavado de activos estudiado en este trabajo de investigación, la auditoría forense cumplió un papel relevante. Y una vez agotados los tres principales pasos de la auditoría: planeación, ejecución y conclusión (Whittington \& Pany, 2000), se profirió la debida sentencia para el principal protagonista en el delito de lavado de activos; a continuación se relacionan esos tres principales aspectos en el caso.

\section{i. Planeación}

La planeación tiene un componente principal: la identificación de piezas fundamentales que permiten hacer una adecuada y satisfactoria planeación, y enfocar las pruebas según la relatividad del caso. Las siguientes son las pruebas más contundentes que lograron ser parte principal en esta investigación:

- El hecho de que el jefe de la Sijin, por medio de la observación (Estupiñán-Gaitán, 2006), identificara movimientos sospechosos en un determinado sector y planeara enviar a un grupo de investigadores para averiguar qué ocurre.

- El estudio del Código Penal colombiano (Art. 323) para poder definir estos movimientos sospechosos como un supuesto caso de lavado de activos.

- El estudio de pruebas documentales básicas: aspectos previos que permitan conocer el negocio, el sector económico y sus características; conocimiento de los registros contables utilizados; evaluación de posible ocurrencia de otros delitos dentro de este y estudio de pruebas documentales.

- La recopilación de suficiente evidencia con el allanamiento y la incautación para catalogar este caso como de lavado de activos. 


\section{ii. Ejecución}

Con base en la etapa de la planeación, se definieron las siguientes actividades que fueron desarrolladas en la etapa de ejecución:

Transcurso de la investigación (primera parte)

- Detención temporal de Pablo Pérez y Juana Sánchez.

- Escuchar inmediatamente mediante declaración en juicio el testimonio de esta pareja de esposos.

- Remitir bajo custodia las joyas encontradas.

- Consignar los dólares y el dinero en efectivo a la entidad financiera correspondiente.

- Llamar a declaración a testigos, que podrían ser cómplices.

- Evaluar la inocencia o culpabilidad de los dos implicados.

Transcurso de la investigación (segunda parte)

- Detención preventiva del sindicado de lavado de activos.

- No se embargan ni secuestran los bienes del incriminado por desconocer su procedencia.

- Abstención de proferir medida de aseguramiento contra Juana Sánchez y suscripción de boleta de libertad.

- Definición de si se desarrollaba un proceso de apelación o en contra de Pablo Pérez.

- Se envía a Pablo Pérez a la cárcel de Vijes por solicitud de su apoderado.

\section{iii. Conclusión}

Del análisis de las pruebas recabadas en el proceso, se concluyó que la conducta del señor
Pérez giraba en torno a ocultar las divisas enviadas, al introducirlas al territorio nacional, evadiendo los controles; se corroboró entonces su responsabilidad en el punible de lavado de activos, por cuanto no se logró justificar de manera contundente el origen legal de las mismas; por el contrario, el juzgado consideró que el capital era proveniente de actividades ilegales, en las que el procesado actuaba como intermediario, cuando además — teniendo la oportunidad procesal para ejercer su derecho de defensa y demostrar lo contrario- no logró demostrar en forma clara y coherente el origen de su ingreso.

\section{Conclusiones}

La auditoría responde a la necesidad de identificar el fraude además de controlar y asegurar el adecuado funcionamiento de un área determinada. Con ello, la auditoría tiene diversas formas de aplicarse en diferentes ámbitos y casos; su aplicabilidad en los delitos financieros se denomina auditoría forense.

De acuerdo al desarrollo del trabajo, aplicar el procedimiento de auditoría forense en un caso de delito financiero en particular facilita descubrir, divulgar y atestar este fraude, debido a que este proceso implica imparcialidad para recoger evidencia penal y así mismo dar en firme una decisión respecto al delito.

Inicialmente, el caso escogido para estudio no tiene una estructura referente al proceso de auditoría ni se ha realizado una investigación previa como tal; no obstante, en su análisis y comparación se puede relacionar, teniendo en cuenta que se identifica una necesidad de 
generar toda una indagación para conocer la verdadera situación de fraude a la que el Juzgado, la Fiscalía, la Sijin, la Procuraduría y demás entes reguladores se enfrentaron. Esta problemática se maneja por medio de un plan de acción vinculado al proceso de auditoría que arroja evidencia suficiente para confirmar la culpabilidad de los implicados; así mismo, se reúnen los argumentos necesarios y se da por terminado el caso mediante una sentencia.

Además, al identificar el proceso de auditoría comúnmente utilizado resumido en planeación, ejecución y conclusión; al estudiar la definición y las características de delito de lavado de activos, se logra establecer la relación del caso escogido directamente del Juzgado del Circuito Penal de la ciudad de Cali, debido a que este implicó manipulación de bienes originados de actividades ilícitas que aparentemente eran legales, pero que en realidad ocultaba, encubría u omitía la verdadera naturaleza de estos bienes.

Este caso se relaciona con la auditoría forense cuando se identifican aspectos como el conocimiento del sector económico: la joyería y los préstamos para compra de bienes y servicios; el análisis de los registros contables en este tipo de compañías; la evaluación de posible ocurrencia de otros delitos; y el vínculo de las pruebas documentales como evidencia de auditoría. La auditoría forense cumplió un papel importante en este caso, debido a que en el transcurso del proceso de delito financiero, los pasos de la auditoría se hacen presentes y en definitiva, se toma la conclusión y/o veredicto que más se ajusta a ley colombiana.

\section{Referencias}

Cano, Miguel \& Lugo, Danilo (2004). Auditoría forense en la investigación criminal del lavado de dinero y activos. Bogotá: ECOE Ediciones.

Cano, Donaliza; Lugo, Danilo; Cano, Miguel \& Cano, José Eriberto (2008). Auditoría financiera forense en la investigación de delitos económicos y financieros, lavado de dinero $y$ activos, y financiación del terrorismo. Bogotá: ECOE Ediciones.

Colombia (1991). Constitución Política. Gaceta Constitucional, 116, 20 de julio de 1991. Versión corregida disponible en: http://www. secretariasenado.gov.co/senado/basedoc/ constitucion_politica_1991.html

Colombia (1990). Ley 43 de 1990, por la cual se adiciona la Ley 145 de 1960, reglamentaria de la profesión de contador público y se dictan otras disposiciones. Diario Oficial, 39.602, 13 de diciembre de 1990. Disponible en: http://www.mineducacion.gov. co/1621/articles-104546_archivo_pdf.pdf Colombia (1997). Ley 365 de 1997, por la cual se establecen normas tendientes a combatir la delincuencia organizada y se dictan otras disposiciones. Diario Oficial, 42.987 de 21 de febrero de 1997. Disponible en: http:// www.secretariasenado.gov.co/senado/ basedoc/ley_0365_1997.html

Colombia (2000). Ley 599 de 2000, por la cual se expide el Código Penal. Diario Oficial, 44.097, 24 de julio de 2000. Disponible en: http://www.secretariasenado.gov.co/senado/ basedoc/ley_0599_2000.html

Colombia (2004). Ley 906 de 2004, por la cual se expide el Código de Procedimiento Pe- 
nal. Diario Oficial, 45.657, 31 de agosto de 2004 (versión corregida en el Diario Oficial, 45.658). Disponible en: http://www. secretariasenado.gov.co/senado/basedoc/ ley_09060_204a.html

Estupiñán-Gaitán, Rodrigo (2006) Control interno y fraudes con base en los ciclos transaccionales. Análisis de Informe COSO I y II. Bogotá: ECOE Ediciones.

Rodríguez-Moguel, Ernesto A. (2005). Metodología de la investigación. Villahermosa, México: Universidad Juárez Autónoma de Tabasco, Colección Héctor MerinoRodríguez.

Ruiz-Limón, Ramón (2006). Historia y evolución del pensamiento científico. Disponible en: http://www.eumed.net/ libros-gratis/2007a/257/index.htm Stake, Robert E. (1999). Investigación con estudio de casos. Madrid: Ediciones Morata.
Whittington, Ray \& Pany, Kurt (2000). Auditoría, un enfoque integral. Bogotá: Editorial McGraw-Hill Interamericana.

- Fecha de recepción: 25 de agosto de 2015

- Fecha de aceptación: 30 de octubre de 2015

- Disponible en línea: 15 de mayo de 2016

\section{Para citar este artículo}

Grajales-Quintero, J.; Hormechea-Jiménez, K. del C. \& Trujillo-Guapacha, B. A. (2015). El papel de la auditoría forense en un caso de lavado de activos en Santiago de Cali. Cuadernos de Contabilidad, 16(42), 713-731. http:// dx.doi.org/10.11144/Javeriana.cc16-42. pafc 
